\title{
Oral health and disease in AIDS workshop planned for Bali
}

Registration for the 8th World Workshop (WW8) on Oral Health and Disease in AIDS is now open and the organisers would like to invite all interested parties to see the programme and to reserve a place on the website www.ww8aids.org.

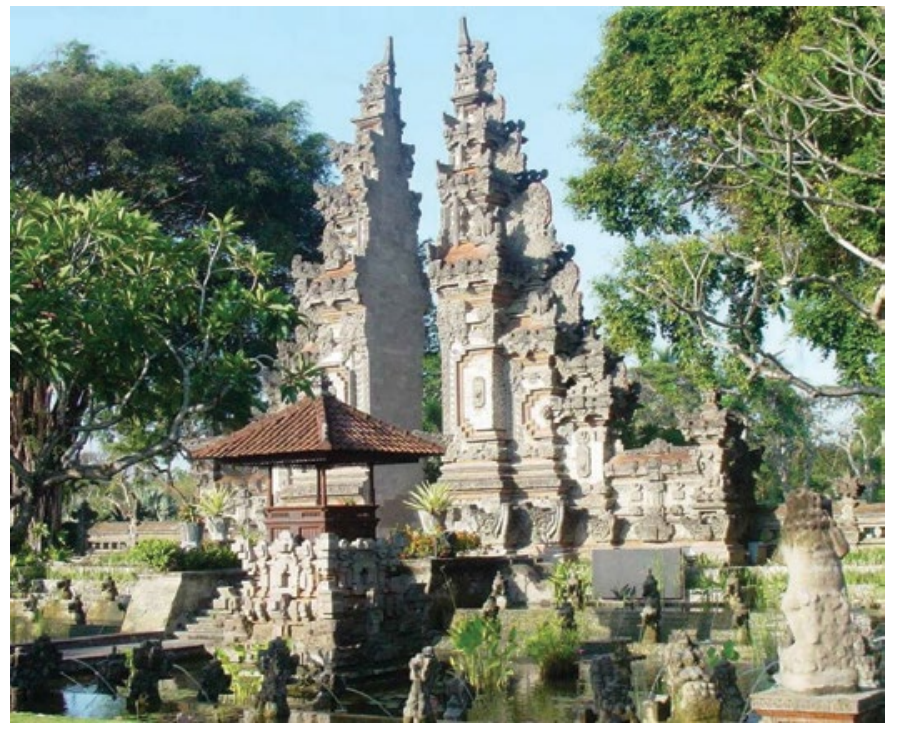

The three-day event will be held in Bali, Indonesia (pictured) from 13-15 September 2019. The event is open to the entire research community, clinicians, patient and partners, and others with an interest in improving the health of people with HIV.

With the title 'Improving Health and Wellbeing', the workshop will focus on the impacts of economic, demographic, and social issues of HIV/AIDS in developing countries, HIV-related stigma and discrimination in dental healthcare settings, and the advances in research and innovation in HIV/AIDS.

An understanding of these issues is critical in taking steps to address the global HIV epidemic and reduce health disparities.

The benefits of anti-retroviral therapy are widely recognised and yet access to this medication is not universally adopted by patients who would benefit. By sharing the latest research and developing a consensus view on what needs to be done to close that gap, this workshop provides the international Clinical community with a powerful instrument to share with fund holders back home. The future research agenda for the subject will be discussed and established at this workshop.

The programme has been organised by an International Steering Committee working in conjunction with the Indonesian Dental Association. The proceedings of the meeting will be published in an open access international journal in due course. www.ww8aids.org.

\section{BDJ $\frac{\text { RESEARCH INSIGHTS }}{\text { FOR ANOTHER VIEW }}$}

Research insights from across the BDJ Portfolio

- Providing busy readers with valuable context including article summaries and expert commentary

Catch up here: http://bit.ly/BDJResearchlnsights

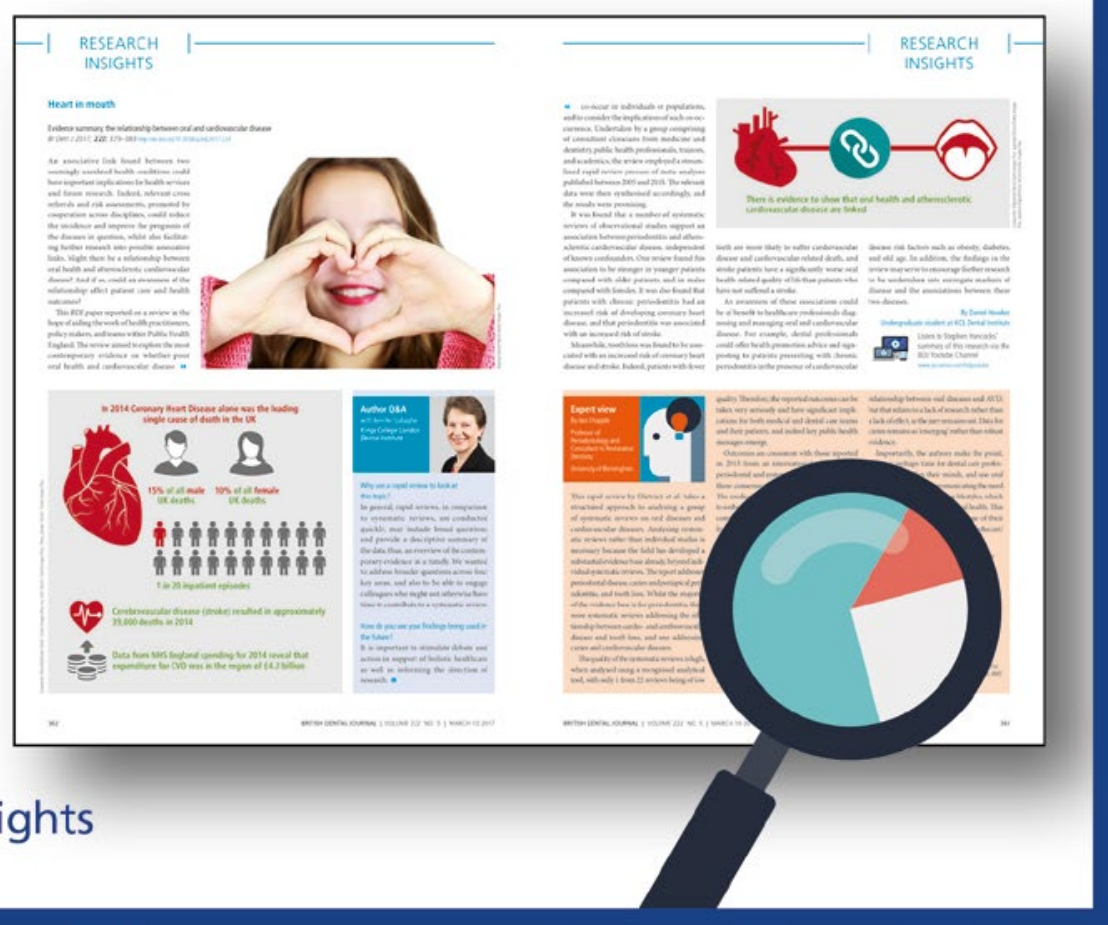

